\title{
COSTA, Renata Ferreira. Apropriação de fontes textuais no século XVIII: o caso da memória histórica da capitania de São Paulo. São Paulo: Blucher, 2018. 176p.
}

Antonio ACKEL ${ }^{1}$

O livro sobre o qual se resenha - Apropriação de fontes textuais no século XVIII: o caso da memória histórica da capitania de São Paulo - é resultado da tese de doutorado de Renata Ferreira Costa, defendida em outubro de 2012, na Faculdade de Filosofia, Letras e Ciências Humanas da Universidade de São Paulo. Publicado em 2018, propõe reflexões acerca das intervenções que Manuel Cardoso de Abreu empreendeu sobre suas fontes ao compor Memória histórica da capitania de São Paulo e todos os seus memoráveis sucessos desde o ano de 1531 até o presente de 1796.

A obra de Abreu promoveu uma série de questionamentos quanto a sua autoria e acabou sendo considerada plágio, por historiadores brasileiros do século XIX, quando de sua publicação. Abreu, de fato, não fez nenhuma referência aos autores dos longos trechos que retirou de suas obras para a composição de sua Memória histórica.

No entanto, para além de classificar o ato como apropriação indébita, Costa argumenta em seu livro sobre os graus de interferência editorial e as razões que levaram Manuel Cardoso de Abreu a omitir nominalmente os autores intelectuais e como esse processo de intervenções se relacionou com as práticas de escrita da época.

Para tanto, Costa em sua pesquisa procedeu com análises quantitativas e qualitativas das variantes textuais e linguísticas e estabeleceu padrões pelos quais essas lições manuelinas - os conteúdos que Manuel Cardoso de Abreu colocou naquele lugar do texto - se manifestaram. Sua proposta baseou-se na categorização de erros de Blecua (1983): adição, omissão, alteração de ordem e substituição e na categorização de paragrafação e reelaboração de Souza (2011).

1 Universidade de São Paulo (USP), São Paulo, São Paulo, Brasil; antonio.ackel@usp.br; http://orcid.org/0000-0002-8283-4417 
- Apropriação de fontes textuais no século XVIII: o caso da memória histórica da capitania de São Paulo.

A publicação de Apropriação de fontes textuais no século XVIII: o caso da memória histórica da capitania de São Paulo permite o acesso a uma fonte fidedigna para que se compreendam mecanismos de edição de textos de outros autores que Manuel Cardoso de Abreu utilizou para criação de sua nova obra, concebida como genuína. Renata Costa fundamentou-se em pressupostos teórico-metodológicos da (i) Crítica de Fontes, que, segundo Christofe (1996), é uma ciência que se relaciona ao estudo da gênese literária e possibilita a identificação das fontes que propiciaram subsídios para a produção textual; (ii) da Filologia que, segundo Spina (1994), examina a fidelidade das transcrições, cópias e edições e permite estabelecer autoria e procedência de um documento; (iii) e da Crítica Textual, que se ocupa da restituição e fixação da genuinidade de um texto (CANDIDO, 2005).

Ademais, a autora reconstrói o processo de elaboração textual de Manuel Cardoso de Abreu com o intuito de situar a gênese da obra e seus sucessivos estágios de retextualização (MATÊNCIO, 2003). Esse termo refere-se à produção "de um novo texto a partir de um texto-base", pressupondo-se em tal atividade a relação de intertextualidade e interdiscursividade. A partir do entendimento de "texto novo", retextualizar implica uma mudança de propósito, porque não se trabalha mais com o mesmo texto, mas com o novo.

Costa (2012) faz também uma recuperação histórica da palavra plágio, desde sua concepção, da Antiguidade clássica até os meios tecnológicos baseados na rede da Internet, e estabelece relação entre motivações de plágio, intertextualidades, direitos autorais e práticas de escrita.

Sendo Memória histórica um conjunto de operações reproduzidas como uma grande reorganização e adaptação textual "nos níveis sintático, lexical e informacional" (COSTA, 2012, p. 116), a obra parece remontar o princípio da imitatio e da aemulatio, trazendo para o interior de sua construção textual uma série de imitações e emulações de uma tradição literária que também se estabeleceu em torno da intertextualidade, da retomada de autores e gêneros como parte de um modo específico de produção.

No tocante às motivações plagiárias, em comparação ao conto de Borges (1944), Pierre Menard, autor do Quijote - uma retextualização de Miguel de Cervantes -, a autora oferece uma possibilidade de interpretação de Memória histórica que destitui "a ideia da identidade fixa de um texto [...], em detrimento da leitura, da interpretação e da releitura" (COSTA, 2012, p. 103), já que todo pensamento pode se deixar ser influenciado.

Em seu trabalho, a intertextualidade é concebida a partir da visão bakhtiniana que promove o diálogo entre os textos, buscando em todos eles fragmentos favoráveis ou 
contrários para a construção de um novo texto. Tal entendimento nos leva à compreensão de que atos de escrita se dão pela presença de textos anteriores. Assim, pode-se dizer que um texto não possui um autor único, mas que é constituído por muitas vozes autorais que dialogam no tempo e no espaço.

No poema "A invenção de um modo", Adélia Prado (2015) corrobora com a definição de intertextualidade, quando diz: "Porque tudo que invento já foi dito nos dois livros que eu li: as escrituras de Deus, as escrituras de João. / Tudo é Bíblias. / Tudo é Grande Sertão".

Juridicamente, Costa (2012, p. 104) mostra que o plágio reside no dolo, como o roubo, e só se configura como tal quando for "ipsis verbis e integral". No entanto, propõe uma reflexão sobre a não existência de um autor sem influências. Faz-nos pensar que, de fato, não existem obras sem antecedentes, que não existem textos sem memórias.

A sociedade de historiadores do Brasil, no século XIX, compartilhava de um senso crítico sobre os modos de escrever história. Afonso d'Escragnolle Taunay, assim como outros acadêmicos, entendeu que a obra de Manuel Cardoso de Abreu era plágio.

Costa aponta que tal visão careceu de uma análise aprofundada da tradição historiográfica de produção textual, a partir de um ou mais textos-base, nascida na Antiguidade. O próprio Taunay, ao compor Os princípios gerais da moderna crítica histórica (1914), apoiou-se majoritariamente na dissertação de Carl Friedrich Phillip Von Martius, Como se deve escrever a história do Brasil (1845), e em estudos variados de seu mestre, Capistrano de Abreu.

Ademais, Taunay, tendo colacionado os textos utilizados como modelo, ao levantar questões de autoria sobre a obra de Manuel Cardoso de Abreu, parece não ter se preocupado em discutir as variantes existentes na obra nem as razões que levaram Abreu àquela produção. Segundo Costa (2012), o historiador não aborda as novas interações textuais que Abreu propôs por meio de um novo rol de referências.

Os autores utilizados como modelo por Abreu são Pedro Taques Paes Leme e Frei Gaspar Madre de Deus. Figuras notáveis no Brasil, foram os primeiros historiadores a pesquisar fontes em arquivos, câmaras e cartórios na elaboração de suas obras, o que lhes assegurava resultados fidedignos, apoiados em dados documentais.

Tal característica de pesquisa tem forte ligação com a tradição de estudos iniciada no final do século XVII, na Europa, preconizada por Jean Mabillon (1681), quando formulou princípios gerais para um método científico de pesquisas históricas baseadas em fontes documentais autênticas. 
- Apropriação de fontes textuais no século XVIII: o caso da memória histórica da capitania de São Paulo.

De outra forma, Costa (2012), sob perspectiva historiográfica que toma as fontes documentais por dados empíricos antes da autenticidade ser posta à prova (RÜSEN, 2007), alerta para a compreensão que se deve ter sobre o que legitima o documento, dissociado da verdade. Segundo Rüsen (2007), a pesquisa histórica ampara-se na realidade das experiências do passado, que foram registradas e, portanto, são fontes.

Essa ideia se coaduna com a de "balanço de fontes" que Spina (1955) propôs ao discutir a Crítica de Fontes. Ao abordar a questão, Spina (1995, p. 13-14) trata da distinção entre fonte, que consiste na "reprodução de um episódio, de uma situação, de uma ideia, uma imagem ou mesmo de um tema" e influência, que consiste na "imitação de processos de composição, de estilo (no seu amplo sentido de expressão literária e concepção da vida e do mundo)".

Manuel Cardoso de Abreu utilizou-se de cinco obras para elaboração de sua Memória histórica, quais sejam, Memórias para a história da capitania de São Vicente, de Frei Gaspar; História da Capitania de São Vicente, Notícia Histórica da Expulsão dos Jesuítas do Colégio de São Paulo e Nobiliarquia Paulistana Histórica e Genealógica, de Pedro Taques e Divertimento Admirável, do próprio Manuel Cardoso de Abreu.

Oficial de vários cargos na Capitania de São Paulo, ainda que não tivesse tido educação formal em pesquisas historiográficas, Abreu foi também autor de narrações sobre a história colonial brasileira, resultantes de suas expedições. Em 1783, enquanto esteve preso por tráfico de joias (COSTA, 2012), escreveu Divertimento Admirável: para os historiadores observarem as máquinas do mundo reconhecidas nos sertões da navegação das Minas de Cuiabá e Mato Grosso.

No início de 1784, liberado do confinamento, voltou a São Paulo, sem recursos financeiros. Foi-lhe oferecida uma posição de enfermeiro no hospital militar. Cinco anos mais tarde, ocupando o cargo de escriturário da Secretaria do Governo de São Paulo, faleceu acometido por uma doença no cérebro aos 56 anos de idade.

Seguindo a mesma tradição literária que fez da intertextualidade um princípio estético, abordado por Renata Costa, o que Manuel Cardoso de Abreu propõe em Memória histórica não são simplesmente imitações, mas emulações de seus autores. Mais, ao descrever os grandes feitos dos antigos paulistas, o autor não se limitou a uma descrição de episódios, mas à história da Capitania de São Paulo desde o início até sua época. Essa Capitania, antes denominada Capitania de São Vicente, era constituída pelos atuais estados de São Paulo, Minas Gerais, Goiás, Tocantins, Mato Grosso, Mato Grosso do Sul, Paraná, Santa Catarina e parte do Rio Grande do Sul. 
Em Memória histórica da capitania de São Paulo e todos os seus memoráveis sucessos desde o ano de 1531 até o presente de 1796, Manuel Cardoso de Abreu remonta o épico passado de heroicas superações de desafios fantasiosos que, segundo Costa (2012, p. 34), são uma narração "tingida com certa tintura épica, pois sua matéria é justamente a lembrança e exaltação do passado.".

A obra de Abreu encerra-se com descrições dos modos de administração do governo de Francisco da Cunha e Menezes e com a notícia da posse do então Capitão General da Capitania, Bernardo José de Lorena, para governar a Capitania de Minas Gerais.

Manuel Cardoso de Abreu, diferentemente dos autores que the serviram de modelo, não faz um recorte na história. Propõe emular tudo o que é possível em termos textuais desde o início até o que se tinha de conhecimento sobre os locais que teria percorrido. Mais do que contar toda a história, Abreu procurou traçar o desenvolvimento épico da Capitania de São Paulo.

Com esta obra, Renata Ferreira Costa convida a conhecer o processo intertextual operado por Manuel Cardoso de Abreu, em que diferentes textos são colocados a serviço do autor, mas há, sem dúvida, destaque para as apropriações que ele faz, a seu modo e muitas delas não apenas imitando outros autores, mas os colocando em outra dimensão e até mesmo ampliando ou revendo o que eles pretendiam em seus textos.

Esta resenha convida o leitor, interessado na história da concepção e da transmissão de obras setecentistas, como Memória histórica, cuja autoria é passível de questionamentos, a conhecer a trama textual que Abreu enredou, ao compor sua obra e que, nas palavras de Renata Costa, "não pode ser considerada um plágio, mas uma retextualização a partir de textos alheios".

A autora propõe uma leitura subjacente aos historiadores do passado, na medida em que reflete, à luz da crítica de fontes, filologia e crítica textual, sobre as operações textuais de Manuel Cardoso de Abreu e suas relações com outros autores, textos e práticas de escrita.

Ainda, àqueles que porventura se interessarem em se aprofundar no assunto que Renata Ferreira Costa analisou durante sua pesquisa de doutorado, sua tese, disponível em teses.usp.br, apresenta estudos codicológicos, paleográficos sobre a documentação e análises linguísticas que incluem a elaboração de um glossário parcial, índices de expressões latinas, antropônimos, topônimos e outros apontamentos que asseguraram a elaboração do livro que ora se apresenta. 
- Apropriação de fontes textuais no século XVIII: o caso da memória histórica da capitania de São Paulo.

\section{Referências}

BLECUA, A. Manual de Crítica Textual. Madrid: Castalia, 1983.

BORGES, J. L. Pierre Menard, autor del Quijote. In: BORGES, J. L. Ficctiones. Madrid: Aliança Editorial, 1944.

CANDIDO, A. Noções de análise histórico-literária. São Paulo: Humanitas, 2005.

CHRISTOFE, L. Intertextualidade e Plágio: questões de linguagem e autoria. 1996. Tese (Doutorado em Letras) - Instituto de Estudos da Linguagem, Universidade Estadual de Campinas, Campinas, 1996.

COSTA, R. F. Apropriação de Fontes Textuais no Século XVIII: o caso da Memória Histórica da Capitania de São Paulo. 2012. Tese (Doutorado em Letras) - Faculdade de Filosofia, Letras e Ciências Humanas, Universidade de São Paulo, São Paulo, 2012.

MABILLON, J. De re diplomatica. Paris: Libri IV, 1681.

MATÊNCIO, M. L. M. Atividades de (re)textualização em práticas acadêmicas: um estudo do resumo. Scripta, v. 6, n. 11, p. 109-122, 2003.

PRADO, A. Poesia reunida. Rio de Janeiro: Record, 2015.

RÜSEN, J. Reconstrução do passado. Teoria da história II: os princípios da pesquisa histórica. Brasília: Universidade de Brasília, 2007.

SOUZA, L. B. D. Frequência das variantes do romance $O$ Seminarista, de Bernardo Guimarães. Anais do XV Congresso Nacional de Linguística e Filologia. v. XV, n. 5, t. 1. Rio de Janeiro: CiFEFil, 2011. p. 588-601.

SPINA, S. A Crítica de Fontes. Da Idade Média e de Outras Idades. São Paulo: Conselho Estadual de Cultura - Comissão de Literatura, 1955. p. 7-25.

SPINA. S. Introdução à Edótica: Crítica Textual... São Paulo: EDUSP, 1994.

TAUNAY, A. E. Os princípios gerais da moderna crítica histórica. RIHGSP, v. XVI, p. 323$344,1914$. 
COMO CITAR ESTA RESENHA: COSTA, Renata Ferreira. Apropriação de fontes textuais no século XVIII: o caso da memória histórica da capitania de São Paulo. São Paulo: Blucher, 2018. Reseha feita por Antonio Ackel. Revista do GEL, v. 17, n. 2, p. 349-355, 2020. Disponível em: https://revistadogel.gel.org.br/

DOI: http://dx.doi.org/10.21165/gel.v17i2.2846

Submetido em: 14/06/2020 | Aceito em: 06/07/2020. 